canal, with only one injection, which allows: blocking of the main nerves involved in shoulder innervation and lower risks of phrenic block and suprascapular nerve block sparing2.

\section{REGIONAL ANAESTHESIA AND SEVERE HAEMOPHILIA. IS A CONTINUOUS FEMORAL NERVE BLOCK SAFE? A CASE REPORT}

G Moreno Giménez*, A Font Gual, C Heredia Carqués, M Rodríguez Prieto, MA Gil de Bernabé Sala. Hospital de la Santa Creu i Sant Pau, Barcelona, Spain

\subsection{6/rapm-2021-ESRA.37}

Background and Aims Peripheral nerve blocks may be used in haemophilia A patients with appropriate Factor VIII (FVIII) values. However, the use of perineural catheters has been poorly documented. We describe a continuous femoral nerve block (CFNB) in conjunction with a sciatic nerve block (SNB) to control perioperative pain in a severe haemophilia A patient undergoing total knee arthroplasty (TKA).

Methods We report a case of a 51-year-old man with severe haemophilia A scheduled for TKA. 15 minutes after administering 3000 IU of intravenous recombinant FVIII, a combination of ultrasound-guided SNB and CFNB was performed. The needle was inserted in-plane, from lateral to medial. An initial bolus of $15 \mathrm{~mL} 0.2 \%$ Ropivacaine was injected in each block, followed by an $8 \mathrm{~mL} /$ hour continuous femoral nerve perfusion. Afterwards, a total intravenous anaesthesia was required. $2000 \mathrm{IU}$ of recombinant FVIII every 12 hours for the first 3 postoperative days and then every 24 hours were administered. Bemiparin thromboprophylaxis was initiated on the second postoperative day and the femoral catheter was removed on the third without incidents.

Results FVIII levels above 100\% were maintained throughout admission. No complications from the regional blocks were reported. The score of pain was maintained less than 3 within 72 hours after surgery that facilitated early joint mobilization.

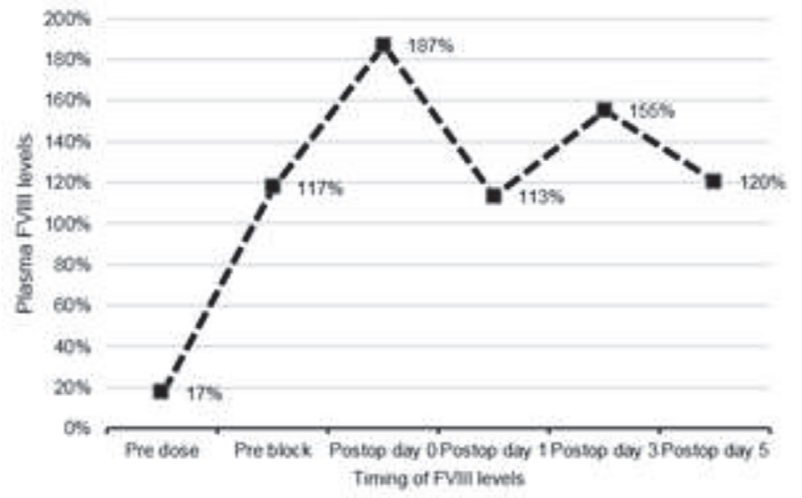

\section{Abstract 37 Figure 1}

Conclusions CFNB may be performed in haemophilia A patients. Nevertheless, it is important to carry out an individualized assessment of the risk-benefit of the technique, a multidisciplinary approach to guide FVIII replacement, and a close follow-up to identify possible bleeding or neurological complications.

\section{Central nerve blocks}

\section{NEURAXIAL DRUG ADMINISTRATION ERRORS FROM 40 COUNTRIES - PRACTICAL ISSUES AND HUMAN FACTORS}

${ }^{1} S$ Patel ${ }^{*},{ }^{2} \mathrm{R}$ Paskaleva, ${ }^{3} \mathrm{D}$ Agrawal. ${ }^{1}$ Tawam Hospital, Al Ain, United Arab Emirates ${ }^{2}$ Airedale NHS Foundation Trust, Airedale, UK; ${ }^{3}$ North Manchester General Hospital, Manchester, UK

\subsection{6/rapm-2021-ESRA.38}

Background and Aims We reviewed country-wise reporting of neuraxial route drug administration errors.

Abstract 38 Table 1 Neuraxial errors reporting countries.Number represents number of patients

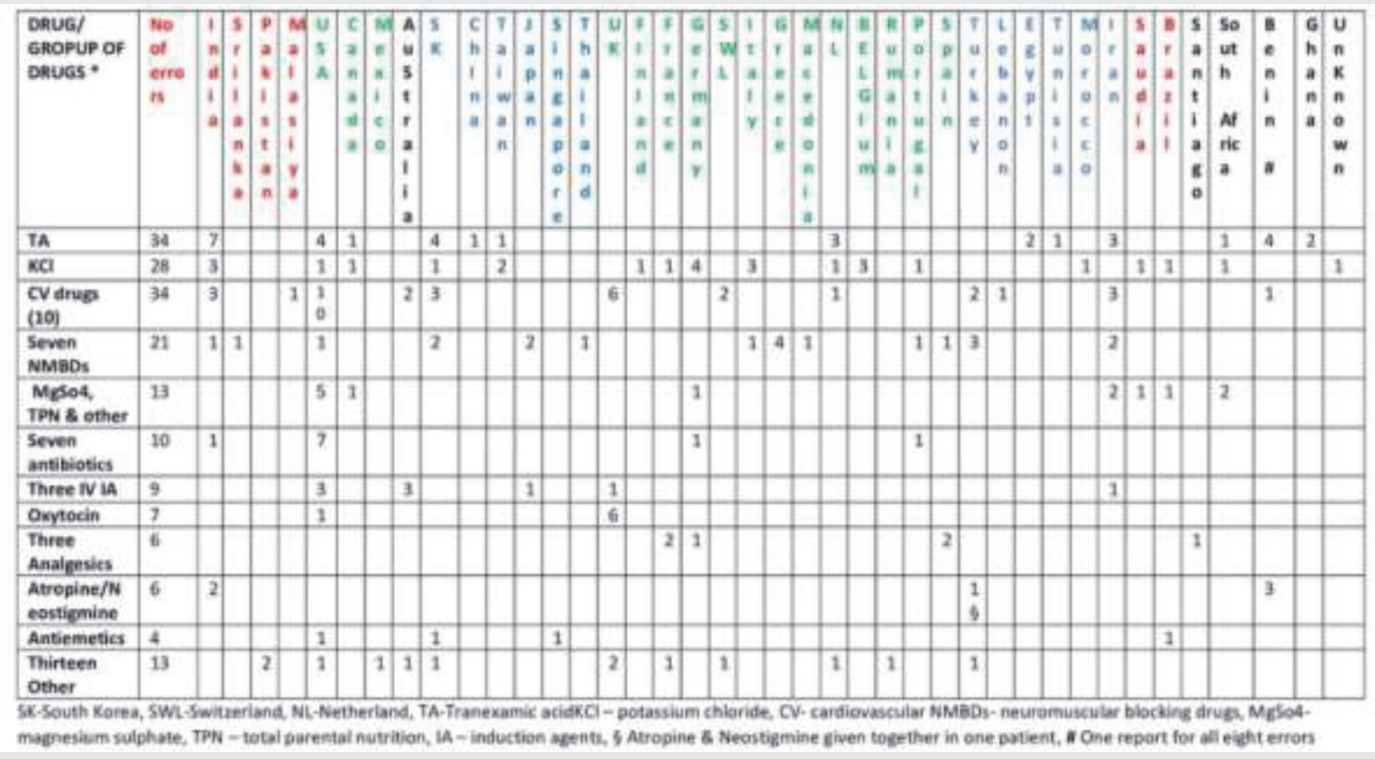


Methods Medline and Google scholar database were searched for neuraxial drug errors through February 2021 using terms including 'epidural drug error'. The search was also done using 'intrathecal' and 'neuraxial' words in place of epidural. Local anaesthetic (LA) and opioids errors were excluded. Medication errors were grouped, countries reporting recorded and industry issues and human factors were identified.
Results 185 neuraxial drug administration errors were reported from 40 countries involving different group of drugs (table 1). $47.5 \%$ errors were reported from 5 countries: USA (33), UK (15), India (17), Korea (12) and Iran (11). Other 5 countries reported $\geq 5$ to 10 errors: Benin (8 in a single report), Germany (7), Turkey (7), Netherlands (6), Australia (5).

Abstract 38 Table 2 Some pharmaceutical and practice issues among countries reporting errors

\begin{tabular}{|c|c|c|c|}
\hline Druej/Onis eroupi & Fatients & 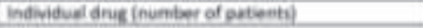 & Pharmacevical company and practice reisted problems \\
\hline Tranesamic acid & 34 & & 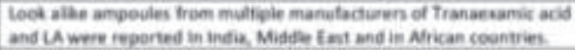 \\
\hline Cardievascular drups & 34 & 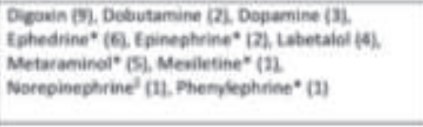 & 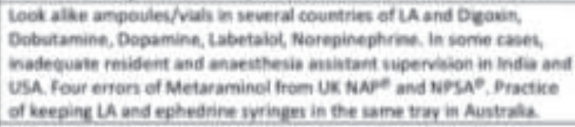 \\
\hline Potaniium Chieride & 21 & & 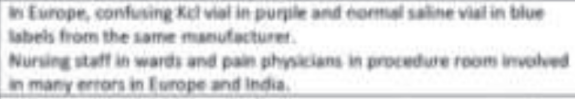 \\
\hline $\begin{array}{l}\text { Neuromatcular blockine } \\
\text { arue }\end{array}$ & 21 & 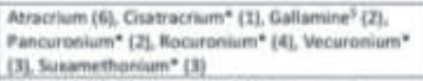 & 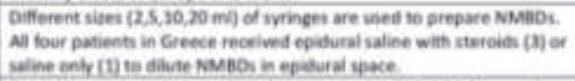 \\
\hline $\begin{array}{l}\text { Flectrolves/ciucese } \\
\text { iefusions and TPN }\end{array}$ & 13 & 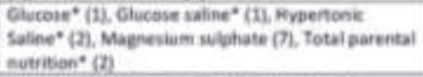 & 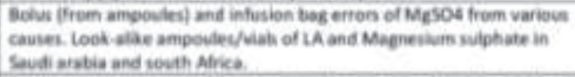 \\
\hline Amtibiotias" & 10 & 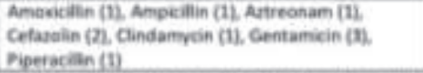 & 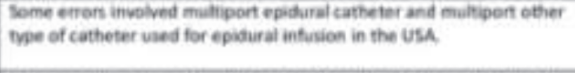 \\
\hline N indertion agents & 9 & 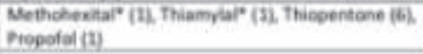 & 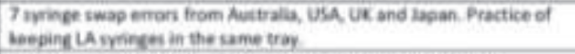 \\
\hline Onnodin* & 7 & & 4. enoh were reperted te harmaceutcal compeny in the UK. \\
\hline Analensia (Nanepioith) & 6 & 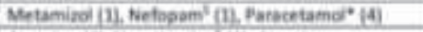 & Four paracetamol infution pump entron from furope \\
\hline Antidolinerec/Chatinerge & 6 & 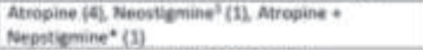 & 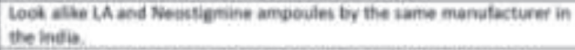 \\
\hline Antiemetirs & 4 & Metaciopramise' $[14$, Ondansetsen (3) & 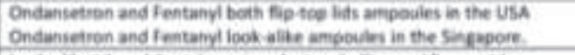 \\
\hline Othen & 13 & 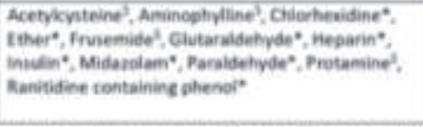 & 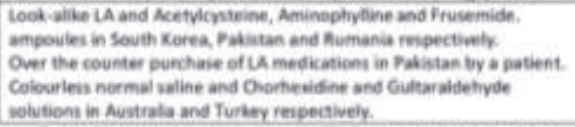 \\
\hline
\end{tabular}

Abstract 38 Table 3 Human factors (www.hfacs.com) identified and their corrections

\begin{tabular}{|c|c|c|}
\hline & Collective human factors inofved in countries & Prevention of erraps \\
\hline $\begin{array}{l}\text { Organinotional } \\
\text { influences }\end{array}$ & 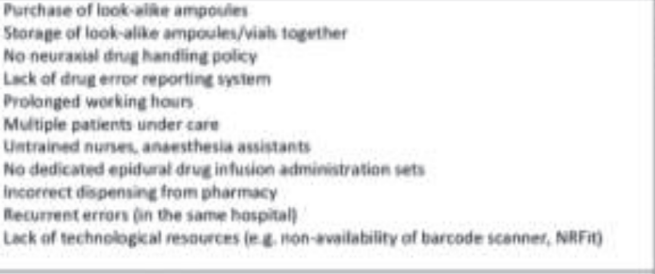 & \multirow[t]{4}{*}{ 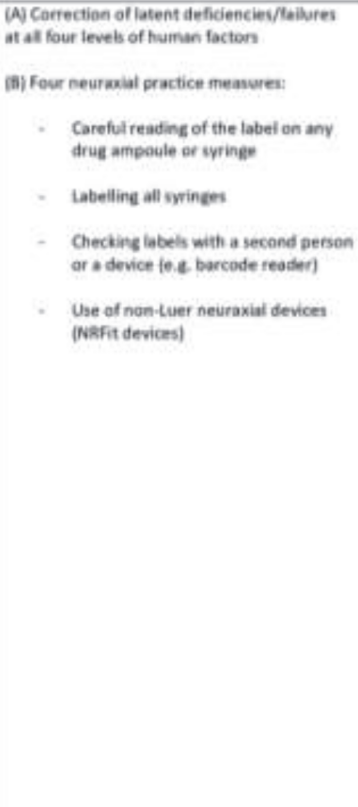 } \\
\hline $\begin{array}{l}\text { Supervisory } \\
\text { factors }\end{array}$ & 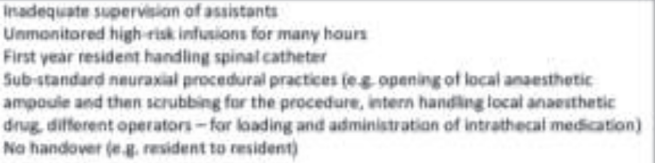 & \\
\hline $\begin{array}{l}\text { Precondition } \\
\text { for unsale acts }\end{array}$ & 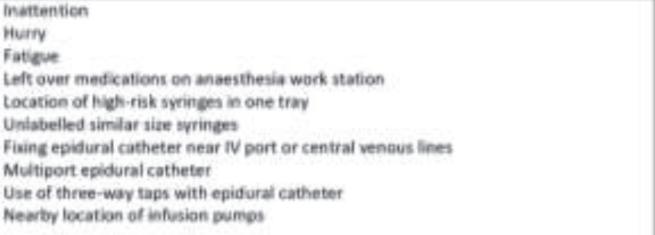 & \\
\hline Unsafe acts & 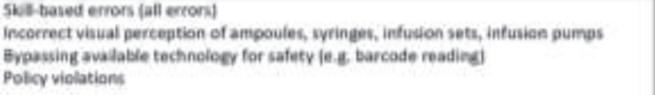 & \\
\hline
\end{tabular}


Off 34 tranexamic acid errors (from 13 countries), 7 occurred in India. 8 European union countries reported 15 (out of 28) potassium chloride errors. Neuromuscular blocking drugs related events were widespread (21 errors from 13 countries). Cardiovascular drug incidents (34) were mainly reported from the USA (9) and UK (6).

Table 2 summarises some issues related to pharmaceutical industry and clinical practice.

Recurrent human factors identified are summarised in table 3 .

Conclusions Manufacturing of look-alike of LA, fentanyl, normal saline and several high-risk ampoules (e.g. tranexamic acid, $\mathrm{KCl}$, digoxin, NMBDs) or vials is one major uniform factor. Robust organisational, supervisory and local clinical practices are needed to correct latent human failures.Universal applications of four recommendations ${ }^{1-4}$ (table 3) would prevent drug administration errors during neuraxial anaesthesia or analgesia.

\section{EFFICACY AND SAFETY OF INTRATHECAL MORPHINE FOR ANALGESIA AFTER LOWER JOINT ARTHROPLASTY: A SYSTEMATIC REVIEW AND META-ANALYSIS WITH META-REGRESSION AND TRIAL SEQUENTIAL ANALYSIS}

${ }^{1} \mathrm{E}$ Gonvers*, ${ }^{2} \mathrm{~K}$ El-Boghdadly, ${ }^{3} \mathrm{~S}$ Grape, ${ }^{1} \mathrm{E}$ Albrecht. 'Lausanne University Hospital, Lausanne, Switzerland; ' ${ }^{2}$ Guy's and St Thomas' NHS Foundation Trust, London, UK; ${ }^{3}$ Hôpital du Valais, Sion, Switzerland

\subsection{6/rapm-2021-ESRA.39}

Background and Aims Widespread adoption of intrathecal morphine into clinical practice is hampered by concerns of its potential side-effects. We undertook a systematic review, metaanalysis and trial sequential analysis with the primary objective of determining the efficacy and safety of intrathecal morphine. Our secondary objective was to determine the dose associated with greatest efficacy and safety.

Methods We systematically searched the literature for any trials comparing intrathecal morphine with a control group in patients undergoing hip, knee arthroplasty under spinal anaesthesia. Our primary efficacy outcome was rest pain score (010) at $8-12 \mathrm{~h}$; our primary safety outcome was the rate of PONV within $24 \mathrm{~h}$.

Results Twenty-nine trials including 1814 patients were identified. Rest pain score at $8-12 \mathrm{~h}$ was significantly reduced in the intrathecal morphine group with a mean difference $(95 \% \mathrm{CI})$ of $-1.7(-2.0,-1.3), \mathrm{I}^{2}=71 \%, \mathrm{p}<0.0001$, without subgroup difference between doses $(\mathrm{p}=0.35)$. Intrathecal morphine increased postoperative nausea and vomiting with a risk ratio $(95 \% \mathrm{CI})$ of $1.4(1.2,1.6), \mathrm{I}^{2}=4 \%$, $\mathrm{p}<0.0001$. However, a subgroup analysis according to doses revealed that rates of PONV within $24 \mathrm{~h}$ was similar between groups with doses of $100 \mu \mathrm{g}$, while the risk significantly increased with doses above ( $p$ value for subgroup difference $=0.03$ ). The quality of evidence for our two primary outcomes was high and moderate-to-high for the secondary outcomes.

Conclusions There is high level evidence that intrathecal morphine provides effective analgesia after lower limb arthroplasty but at the expense of an increased profile of sideeffects. However, a dose of $100 \mu \mathrm{g}$ represents a ceiling dose for analgesia and a threshold dose for increased rate of PONV.

\section{DEVELOPMENT OF A REGIONAL ANAESTHESIA SERVICE FOR RIB FRACTURES: A QUALITY IMPROVEMENT PROJECT}

A Ee* ${ }^{*}$ T Rees. Royal Gwent Hospital, Newport, UK

\subsection{6/rapm-2021-ESRA.40}

Background and Aims Trauma audit research network (TARN) data for 2018 indicated that 100 patients are admitted with chest wall injuries. Retrospective audit of referrals confirmed long length of stay (median 14 days), with 59\% requiring level $2 / 3$ care and $11 \%$ mortality risk.

Regional anaesthesia was offered to less than $25 \%$ of patients despite $63 \%$ reporting severe pain. We decided to introduce an Erector Spinae plane (ESP) catheter service for these patients with aims of reducing length of stay and pain scores.

Methods We set up an email alert system, where TARN data collectors notified us when patients were admitted through the Emergency department with rib fractures. Using Whatsapp, we organised a group of regional anaesthetists who were willing to provide an ESP service.

Results Mean length of hospital stay was reduced from 10 to 7 days after introduction of the service with significant reduction in variability.

Mean pain scores improved from $8.9 / 10$ to $5 / 10$ with an average improvement of pain score of 2.78 points on a numerical scale out of $10 .(n=9)$

Conclusions This was an easy, cost-neutral intervention that has made a noticeable difference in a short time frame. The small reduction in pain scores may be explained by the presence of concurrent injuries. Ongoing improvements in training should improve reliability of catheter placement and reduce practitioner variation.
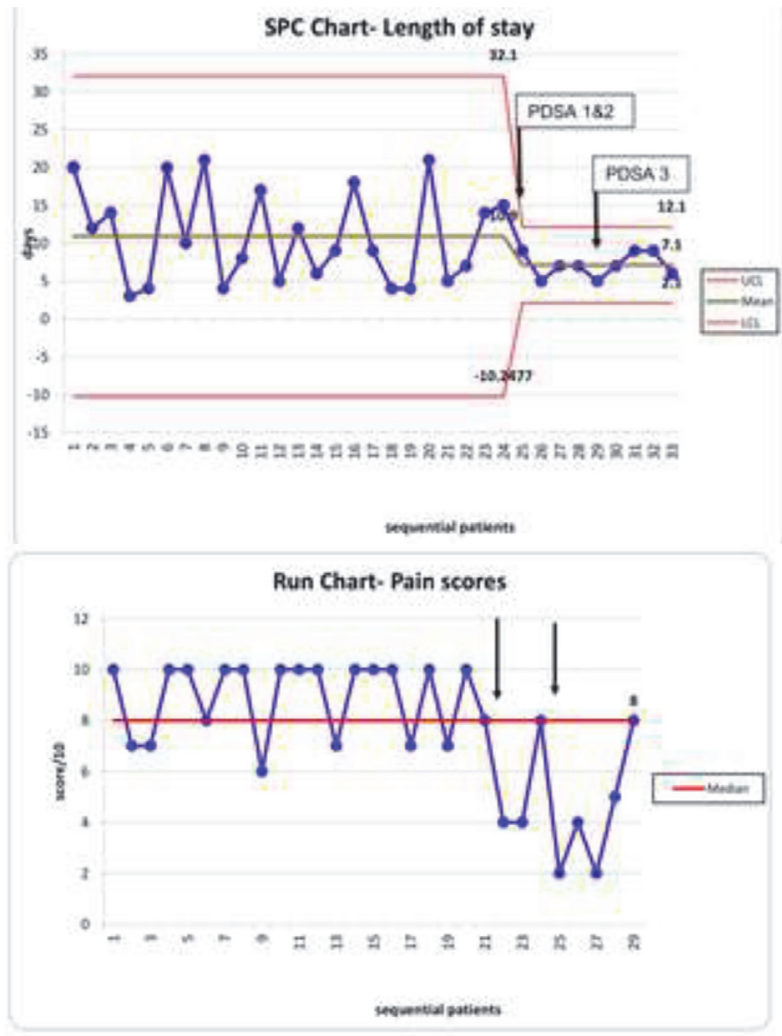

Abstract 40 Figure 1 